\title{
TÉCNICA E NIILISMO: A URGÊNCIA DE UMA NOVA ÉTICA EM HANS JONAS ${ }^{1}$
}

Technique and nibilism: the urgency of a new ethic in Hans Jonas

\author{
José Carlos Moreira \\ Mestre em Filosofia pela \\ FAJE - Faculdade Jesuíta de \\ Filosofia e Teologia, Belo \\ Horizonte MG.
}

RESUMO: Nosso propósito aqui é em linhas gerais mostrar que do advento da técnica que se impõe na era moderna, resulta o niilismo, que por sua vez decreta: o fim da metafísica e o relativismo de valores como "ecos" de um projeto de razão, cuja promessa era em primeira instância, elevar o homem à condição de ser autônomo mediante o saber que o torna capaz de dominar a natureza. Entretanto, se por um lado, a civilização moderna celebra o triunfo da razão demonstrativa, por outro lado, esta mesma civilização, assiste concomitantemente ao abandono da metafísica e da ética, fatores estes que corroboram o niilismo e o relativismo de valores que ora vivemos. Tais fatores levam a uma incerteza em relação à continuidade da vida humana e extra-humana que agora encontra-se ameaçada pelo poder da técnica por meio da ação humana. Como alternativa a este cenário, apresentaremos a teoria da responsabilidade inaugurada por Hans Jonas como a nova ética do futuro, com os seus fundamentos metafísicos e os dois arquétipos que segundo Jonas, melhor representam sua teoria ética. Isto é, a responsabilidade do estadista e aquela dos pais em relação aos filhos. Se a técnica e o niilismo dela decorrente nos apontam para um cenário de incertezas em relação ao futuro, destacaremos essas duas formas de responsabilidades como via de superação do niilismo. Em Jonas a responsabilidade como tarefa do homem de Estado, consiste em assegurar no presente a possibilidade de que no futuro haja homens capazes de assumir responsabilidade. De igual modo, a responsabilidade dos pais em relação aos filhos trata-se de cuidar da vida. O que abri caminhos para a possibilidade de continuidade da existência de vidas no mundo de amanhã, pois o nascimento de uma criança representa o recomeço da humanidade. Sendo assim, a responsabilidade dos pais para com os filhos definirá no presente, um novo sujeito para um futuro novo.

PALAVRAS-CHAVE: Técnica; niilismo; responsabilidade.

\footnotetext{
${ }^{1}$ Parte do presente texto foi apresentado no colóquio Hans Jonas realizado na UFRJ Rio de Janeiro, entre os dias 7 e 9 de dezembro de 2016.
} 


\section{INTRODUÇÃO}

Nosso objetivo neste artigo será mostrar de que modo atécnica moderna e o niilismo relativista dela decorrente, nos impõe a urgência de uma nova ética a partir do pensamento de Hans Jonas. Para tanto, para realizarmos a tarefa a qual nos propusemos, será necessário trilharmos aqui três passos. No primeiro, mostraremos o apogeu da técnica e o niilismo relativista como "ecos" da era moderna. Sublinharemos o niilismo como a falta de sentido que emerge quando se dissolve o poder vinculante das respostas tradicionais ao por que da vida e do ser. $\mathrm{O}$ que nos resta então? Nesse caso, mostraremos que nos resta uma realidade sem diretriz. O mundo já não tem valor em si mesmo. Antes o seu valor tradicional era dado pelo homem. Contudo, com o advento da tecnologia e da biotecnologia moderna, assistimos em nossos tempos, uma indiferença em relação ao ser e o não-ser. Se por um lado, a civilização tecnológica moderna celebra o triunfo da razão demonstrativa e operacional, por outro lado, ela assiste ao exílio da metafísica o que corrobora o niilismo relativista de nossa era. Dito de outro modo, o advento da técnica moderna impõe o niilismo metafísico, e igualmente o niilismo ético como "ecos" do programa da técnica que consistia em primeira instância, na libertação do homem mediante o saber operacional capitaneado pela técnica que o torna capaz de obter total controle sobre a natureza. Contudo, explicitaremos que o que resta debaixo de nossos pés, é um solo instável e um cenário que não nos aponta nenhuma direção segura.

Frente a este cenário de incertezas que a técnica moderna nos lega, Hans Jonas constata a necessidade de uma nova ética. Jonas entende que só uma ética metafisicamente fundamentada, é capaz de se colocar como possibilidade de resgate do ser - valor, da finalidade, portanto, da metafísica. Para tanto, como alternativas ao niilismo, apresentaremos a duas possíveis vias de sua superação: a responsabilidade dos pais em relação aos filhos - parental e a responsabilidade política (coletiva). Isso nos leva a uma questão com a qual precisamos nos ocupar no percurso desta reflexão, qual seja: em que medida essas duas formas de responsabilidades podem se colocar como vias de superação do niilismo relativista o qual herdamos do apogeu que atingiu a técnica na era moderna?

Como primeira via de superação do niilismo, analisaremos a responsabilidade parental, cuja finalidade consiste em educar para tornar o filho adulto e responsável e isto representa um resgate da teleologia - valor, em tempos em que o afã tecnológico e biotecnológico, impõe o relativismo dos valores. Por isso, mostremos qual é essencialmente a tarefa da responsabilidade parental, isto é, a de preservar o bem e o valor - cuidar da vida. Nenhuma criança pede para 
nascer em qualquer que seja as situações, seja privilegiadas ou não. Porém, Jonas considera que o nascimento de uma criança representa concomitantemente o recomeço da humanidade, o que por sua vez, abri caminhos para a possibilidade de continuidade da existência de vidas no futuro longínquo. É este o "resultado" que se espera da responsabilidade enquanto dever fazer aplicada ao âmbito parental - a continuidade da existência humana no mundo. Esta, portanto trata-se da primeira resposta ética, a qual exige a técnica e o niilismo relativista de nossos tempos.

Finalmente, no ultimo passo de nosso artigo, destacaremos a responsabilidade política (coletiva) como resposta ética e segunda via de superação do niilismo. Mostraremos que a preocupação de Jonas com a continuidade da humanidade e da responsabilidade além da esfera parental se estende também ao âmbito político, por isso mesmo, ele propõe a responsabilidade política como segundo modelo paradigmático para pensar a ética. Eis a nossa tarefa nesse artigo, e já que anunciamos o que faremos, agora é ora de realizarmos o que prometemos. Passaremos, portanto, ao primeiro ponto deste trabalho.

\section{1- O APOGEU DA TÉCNICA E O NIILISMO RELATIVISTA: "ECOS” DA ERA MODERNA}

A técnica moderna é dominada por aquilo que Martin Heidegger caracterizou como o desabrigar que em nossos tempos se mostra como um desafio - o niilismo o qual se hospeda na casa humana como Nietzsche assim dizia, causando a diluição de nossas diretrizes, nos impondo uma realidade obscura - a crise. A era moderna não oferece nenhuma direção, sentido ou valor ao homem. Sendo assim, ela expressa o seu mais intenso niilismo. É isso o que faz com que, segundo Jonas, o "niilismo moderno seja infinitamente mais radical e desesperado do que o niilismo gnóstico" (RG, p. 349, apud, OLIVEIRA, J. 2014. p. 125). O niilismo se mostrou como o resultado de um mundo sem Deus, e isto decretou o fim dos valores tradicionais e transcendentes. Já que os valores supremos se depreciaram, agora, a era moderna padece pela falta de finalidade. O niilismo, nas palavras de Franco Volpi é "pois, a "falta de sentido" que desponta quando desaparece o poder vinculante das respostas tradicionais ao porquê da vida e do ser" (VOLPI, F.1999, p. 55). Resta-nos então uma realidade sem diretriz. O mundo - natureza não tem valor em si mesmo, antes sendo o seu valor tradicional, "dado pelo homem - que por fim se tornará ele próprio um ser do qual não se pode dizer que seja também um fim em si, como bem o tem atestado a tecnologia e a biotecnologia moderna e isso leva a uma indiferença em relação ao ser e o não-ser.” (LOPES, W. 2008. p.32). 
Se por um lado, a civilização tecnológica moderna celebra o triunfo da razão demonstrativa e operacional, por outro lado, ela assiste ao exílio da metafísica o que corrobora o niilismo relativista de nossa era. Dito de outro modo, o advento da técnica moderna impõe o niilismo metafísico, e igualmente o niilismo ético como "ecos" do programa daquela, cuja promessa consistia em primeira instância, na emancipação do homem mediante o saber operacional capitaneado pela técnica que o torna capaz de obter total controle sobre a natureza. Entretanto, tal programa com o seu poder de ação, mostra sua face obscura, a qual torna-se um risco para o próprio homem, pois o progresso científico-tecnológico, transformou-se naquilo que Jonas chamou de "Prometeu definitivamente desacorrentado" (PR. 2006, p. 21)2. Tal constatação, no entanto, coloca em dúvida, as condições globais da vida humana, o futuro da espécie e da natureza como um todo.

Como se vê, a já “enorme capacidade de ação decorrente do saber científico e tecnológico não cessa de aumentar, com sempre menos regras capazes de exercer um efetivo controle" (NEDEL, J. 2006, p. 146). Produziu-se, com o poder desmedido conferido à razão, um profundo “vácuo ético" (PR. p. 21) que também é “o vácuo do relativismo de valores atual” (Ibidem, p. 21). Com o ruir das grandes narrativas e a negação da fé na Revelação, e na validade de seus princípios, "afirmou-se a ciência como única fonte de verdade, com o que se perderam os fundamentos dos quais teria sido possível deduzir normas éticas para regular o progresso tecnológico” (NEDEL, J. 2006, pp. 146-147). Agora, nas palavras de Jonas,

Trememos na nudez de um niilismo no qual o maior dos poderes se une ao maior dos vazios; a maior das capacidades, ao menor dos saberes sobre para que utilizar tal capacidade. Trata-se de saber se, sem restabelecer a categoria do sagrado, de cabo a rabo pelo Aufkelärung (Iluminismo) científico, é possível ter uma ética que possa controlar os poderes extremos que hoje possuímos e que nos vemos obrigados a seguir conquistando e exercendo. (PR. 2006, p. 21.).

Ao alcançar seu apogeu, a técnica moderna impõe o niilismo. Com isso, como bem observa Franco Volpi, a situação do homem contemporâneo é de incerteza e precariedade. Pois, "lembra a de um andarilho que há muito caminha numa área congelada e, de repente, com o degelo, se vê surpreendido pelo chão que começa a se partir em mil pedaços. Rompidos a estabilidade dos valores e os conceitos tradicionais, torna-se difícil prosseguir o caminho" (VOLPI, F. 1999, p. 7). O niilismo, continua o autor, constitui uma situação de "desnorteamento provocado pela falta de referências tradicionais, ou seja, dos valores e ideais que representavam

\footnotetext{
${ }^{2}$ Como esta trata-se da obra magna de Jonas a qual constitui a chave mestra para a nossa reflexão, na sequência deste artigo, a citaremos sempre com as iniciais PR. Outras obras de Jonas e demais autores, citaremos de acordo com a formula autor data.
} 
uma resposta aos porquês e, como tais, iluminavam a caminhada humana" (Ibid.1999, p. 8). Vêse, pois, que sem a referência dos valores tradicionais, o niilismo emerge como a face 'escura' de uma era cujo arcabouço técnico, nos revela como já vimoso vazio de sentido que se mostra quando sucumbi o poder e o valor vinculante das respostas tradicionais ao porquê da vida e do ser. Isto

É o que ocorre ao longo do processo histórico no decorrer do qual os supremos valores tradicionais que ofereciam resposta aquele "para quê?" Deus, a verdade, o bem - perdem seu valor e perecem, gerando a condição de "ausência de sentido" em que se encontra a humanidade na sociedade contemporânea (Ibid, p. 57).

A modernidade conferiu primazia à técnica objetivando o homem e o seu bem viver, no entanto, o que resulta da técnica é justamente o vazio de sentido que emerge da dilaceração do ser e dos valores vinculantes. Destarte, o homem permanece um enigma para a ciência e a técnica moderna as quais são incapazes de fornecer sentido à existência humana. (Cf. OLIVEIRA, C. 2013. p. 51). A técnica não é capaz de conferir o sentido do viver para o homem moderno, pois ao desafiar e exilar a metafísica, ela impõe o que Martin Heidegger, chamou de "esquecimento do ser."

Frente ao niilismo metafísico e igualmente o niilismo ético que resultam da face obscura do progresso tecnológico moderno, Hans Jonas constata a necessidade de formulação de uma nova ética para orientar o nosso agir no cenário instável no qual estamos. Segundo o filósofo, é indispensável controlar a "caixa de Pandora do conhecimento científico que abrimos..., fazer uma pausa e pensar realmente onde estamos, para então decidir, com a ajuda da sabedoria, em que direção se deve continuar.” (JONAS, H. 1997, p. 202.)

Sendo assim, diante da ambivalência da técnica, que regula o nosso viver atual, o projeto filosófico de Jonas emerge na contemporaneidade como um referencial no âmbito da ética capaz de lançar luzes sobre o vazio metafísico, ético e a escuridão que ora enfrentamos. A promessa de liberdade da racionalidade tecnocientífica reverteu-se em ameaça e isso nos leva a uma incerteza em relação à continuidade das condições globais de existência. Nesse caso, Jonas entende que

A ética é chamada a responder mesmo metafisicamente às questões do dia, pois, não podemos assistir ao crepúsculo da metafísica. (...). Assistir a chegada de uma tal paisagem sombria. Para "longe de todos os Sóis" é onde tem nos levado a empresa tecnológica de nossa atual civilização. Assim, nos vemos diante de um destino sombrio, onde se nos obrigam a conviver (...) Há que se perceber que a tecnologia, portanto, reclama à ética uma mirada metafísica não só por seu poder meta-físico, e por tornar a própria essência humana objeto de 
sua ação, mas também, e antes de tudo, o seu poder é meta-físico porque nega o próprio âmbito do que é metafísico, o valor do Ser como um todo: a crise que a tecnologia abre, em última instância, é a da questão do valor de tudo aquilo que é objeto de sua ação - aí incluído o homem, a natureza, enfim: o todo do Ser. E é essa crise mais profunda - a crise do valor - que está relacionada com o niilismo. A tecnologia, portanto, se encontra às voltas com o niilismo. (LOPES, W. 2008, p. 29).

Vê-se, pois, que a nossa era moderna se depara com a falta de finalidade. É isto que herdamos após o ruir das grandes narrativas as quais se colocavam como valores vinculantes. Já que a tecnologia e o niilismo relativista dela decorrente fincam raízes no solo da modernidade, agora o que assistimos é, portanto, o relativismo dos valores. Eis, portanto, o cenário, ele, porém, não nos apontam sinais de horizontes claros, ao contrário, todos os sinais que vemos ecoam sons de incertezas. Nesse caso, qual é a saída? Uma possibilidade seria o resgate da teleologia - o bem e o valor. Para tanto, Jonas constata a necessidade da formulação de um novo princípio éticoque seja capaz de afrontar os ecos da era moderna. Com efeito, Jonas entende que uma nova ética para a civilização tecnológica, deve levar a marca de uma ética da responsabilidade e, considerando o sentido da responsabilidade como um dever ontológico, Jonas apresenta dois arquétipos que segundo ele são os que melhor exemplificam sua teoria ética, isto é, a responsabilidade parental e a responsabilidade política. Se de um lado, o afã científico e tecnológico leva ao exilio da metafísica e da ética, de outro, os dois arquétipos destacados pelo filósofo podem ser vias de superação do niilismo relativista de nossos temos, dado que os dois representam o bem e o valor e nesse caso, assegurar o bem e valor, são formas de refutar o niilismo e resgatar a metafísica. Isso nos leva ao segundo ponto no qual destacaremos a responsabilidade parental como uma primeira via possível de superação do niilismo relativista que resulta do apogeu da técnica na era moderna.

\section{2 - A RESPONSABILIDADE PARENTAL: PRIMEIRA VIA DE SUPERAÇÃO DO NIILISMO E DO RELATIVISMO?}

A empresa ética de Jonas toma o futuro como o seu objeto. A preocupação do autor consiste em assegurar indeterminadamente a continuidade da vida humana e suas condições de existência no futuro. A responsabilidade dos pais em relação aos filhos trata-se de cuidar o servida. Embora nenhuma criança peça para nascer em qualquer que seja as situações, sejam privilegiadas ou não, Jonas considera que o nascimento de uma criança representa o recomeço da humanidade, o que por sua vez, abri caminhos para a possibilidade de continuidade da existência de vidas no mundo de amanhã. Sendo assim, a responsabilidade dos pais para com os filhos 
definirá no presente, um novo sujeito para um futuro novo. Isso exige, entretanto, que o dever se manifeste efetivamente, pois sendo a responsabilidade um dever ontológico contido no ser, ele é reivindicado no dever ser dos pais, cuja responsabilidade reverbera como um dever em relação ao recém-nascido. Neste caso o ser - vida reivindica existência, mas a resposta que emana dessa forma de 'poder', não resulta da mera reciprocidade, mas da responsabilidade assimétrica, cuja finalidade se realiza numa via de mão única.

A partir da analogia estabelecida com o recém-nascido Jonas mostra a aplicação da teoria da responsabilidade. Mas o que o filósofo pretende com tal analogia? A pretensão do autor é a de pensar um modo efetivo de assegurar a continuidade da existência de uma humanidade futura. Porém, isso implica um dever, cujo modo de expressá-lo se dá em duas formas: em primeiro plano, para com a existência de uma humanidade futura, independentemente se os nossos descendentes diretos façam parte, e igualmente um dever em relação ao seu modo de ser, isto é, preservar a sua condição (Cf.PR. 2006, p. 90). Em Jonas, o cuidado com o recém-nascido figura como um exemplo que corresponde tanto ao dever objetivo, quanto ao querer subjetivo, em outros termos, a responsabilidade objetiva e seu sentimento subjetivo (Cf. SGANZERLA, A. 2012, p. 212). Desse modo, estaria superada a suposta distância entre ser e dever, porque na constituição do próprio ser, está presente um dever elementar que é concedido pela própria natureza. Com isso, é em relação ao recém-nascido "que o sentimento de responsabilidade apresenta sua força, e convida a responsabilizar-se, constituindo assim a coincidência entre o aspecto subjetivo e objetivo da responsabilidade ética" (Ibidem. p. 212). De acordo com Jonas, responsabilizar-se pelo recém-nascido é também comprometer-se com o todo da humanidade, pois a "esperançosa ideia" de um constante recomeço da humanidade ${ }^{3}$, está atrelado à criança recém-nascida.

A responsabilidade pensada além da ação já realizada, a exemplo do direito civil e penal, representa em Jonas, a busca por um sentido que possa garantir o direito à existência, de modo autêntico, daqueles que ainda não existem. O futuro da teoria da responsabilidade proposta por Jonas é nas palavras de Ricoeur, totalmente antagônico, pois é ainda o futuro dos homens “(...) que agem e que sofrem, mas sob a condição da sobrevivência da humanidade; o novo princípio, portanto, visa apenas ao agir da humanidade futura através de seu viver e de sua sobrevivência." (RICOEUR, P. p. 229, 1996). Com efeito, a sobrevivência da humanidade futura tal como

\footnotetext{
3“Ao olhar o exemplo do recém-nascido Sève aponta que este não pode ser usado como arquétipo porque ele representa o presente, o que faz com que ele se impunha como uma prescrição afirmativa, isto é, como alguém que precisa ser nutrido, cuidado. (1990, p. 86). A esse respeito a posição de Speamann é ainda mais radical, pois afirma que a responsabilidade paterna "não se fundamenta nem sobre um princípio, nem sobre uma máxima, mas sim sobre uma percepção" (1996, p. 283). Ou seja, existe uma exigência à autoconsevação, na medida em que o corpo do ser humano necessita dos outros para a sua sobrevivência". Inserimos aqui a análise já antecipada porSGANZERLA, Anor. Ibidem. 2012, p. 212.
} 
entende Jonas, está condicionada ao novo imperativo ético, cuja orientação consiste em repensar o poder da ação humana no presente, de modo a assegurar o direito de ser no futuro daqueles que não existem.

Os argumentos da ética tradicional de que o direito a reivindicação pertence apenas aquele que existe, tornaram-se insuficientes para a ética do futuro postulada por Jonas. "A tese de que toda vida por si mesma reivindica continuar a viver não pode ser ignorada pela ética, pois mesmo que o ainda não vivente não faça reivindicações, nem por isso pode ter seus direitos negados." (SGANZERLA, A. 2012, p. 212.) Ao lidar com o não existente, a responsabilidade “tem de ser independente tanto da ideia de um direito quanto da ideia de uma reciprocidade, de tal modo que não caiba fazer-se a pergunta brincalhona, inventada em virtude daquela ética: 'o que o futuro já fez por mim? Será que ele respeita os meus direitos?” (PR. p. 89).

O recém-nascido, o qual Jonas usa como arquétipo, coloca em evidência a seguinte situação: mesmo na ausência de reciprocidade, ou na disparidade entre os envolvidos, a criança se torna um sujeito de direitos, embora não possa exercê-los sem a assistência de seus progenitores, e se os seus direitos são exercidos pelos pais, de igual modo são também seus deveres, pois o recém-nascido com sua fragilidade natural não pode cumpri-los. (Cf. COMÍN, 2005, p. 25.) De onde se segue que na elaboração filosófica jonasiana, urge desconstruir o dogma da tradição, de que apenas aquele que existe pode reivindicar direitos. Se o discurso filosófico da tradição construiu o dogma do "não direito dos não nascidos". O principio responsabilidade de Jonas contrapõe àquele da tradição, pois ele visa assegurar o direito à vida daqueles que ainda não nasceram. A responsabilidade dos pais em relação aos filhos corrobora esse direito no futuro. $\mathrm{E}$ a necessária desconstrução do antigo princípio da tradição se impõe, sobretudo em razão da técnica moderna, cujo uso excessivo ameaça à continuidade da vida no futuro. Com isso, o direito de existir deve ser assegurado. Neste caso, a garantia de que no mundo de amanhã existam homens de direito, capazes de decidir, deve ser assegurada por nós no hoje da história, e a teoria da responsabilidade postulada por Jonas a isso se propõe.

A responsabilidade aplicada à relação dos pais para com os filhos é usada por Jonas na elaboração de sua teoria ética como arquétipo da responsabilidade. Desse modo, ela é ao mesmo tempo condição de possibilidade "da articulação entre ser e dever ser e entre ontologia e ética." (JONAS, H. Memorias. 2005. p. 350). O recém-nascido em seu simples ato de respirar dirige aos seus responsáveis um dever irrefutável, pois "na insuficiência radical do recém-nascido está previsto ontologicamente que seus pais o protejam contra sua queda no nada e que se encarreguem de seu devir futuro" (PR. p. 224). Tal exigência implica cuidar da sua existência, independente da compaixão, da misericórdia ou de qualquer outro sentimento. Para Jonas "a 
simples existência de um ser ôntico contém intrinsecamente, e de forma evidente, um dever para outros.” (PR. p. 220) A relação entre pais e filhos usada por Jonas como arquétipo da teoria da responsabilidade que ele postula,

implica um "dever" - em primeiro lugar, um "dever ser" de algo [alguém - a criança], e, em seguida, um "dever fazer" de alguém como resposta àquele dever ser. Ou seja, em primeiro lugar, encontra-se o direito intrínseco do objeto. Somente uma reivindicação imanente ao Ser pode fundamentar objetivamente o dever de uma causalidade do Ser transitivo. A objetividade precisa realmente vir do objeto. (Ibid. p. 219).

Como se observa essa exigência imanente do ser é o próprio ser, ser-dever, ou em outros termos, o direito natural de continuar existindo. Quando a vida do ser, isto é, o recém-nascido exige ser protegida em razão de sua evidente fragilidade, "o imperativo de seguir existindo converte-se em um apelo à responsabilidade de quem tem o poder. Ou seja, a chamada à responsabilidade para o dever ser converte-se em dever, o dever de fazer o todo possível para que se cumpra o imperativo." (SGANZERLA, A. 2012, p. 215.). Nisto se realiza a teoria ética de Jonas aplicada ao âmbito parental. Em tal âmbito, a exigência de responsabilidade para com o recém-nascido urge, e isso sinaliza uma perspectiva de superação do vácuo ético contemporâneo. Se para Jonas, "com cada criança que nasce recomeça a humanidade" (PR. p. 224) podemos, portanto, concluir que com o recém-nascido estará também assegurada a sobrevivência da humanidade no mundo de amanhã. Esta seria uma possibilidade de saída do niilismo metafísico e ético que herdamos do advento da técnica moderna. Entretanto, além deste arquétipo do recémnascido como possibilidade de resgate da finalidade - valor, portanto, da metafísica, a responsabilidade política emerge também como uma segunda via possível de superação dos 'ecos' assombrosos da era moderna: a técnica e o niilismo relativista. Eis a tarefa com a qual nos ocuparemos no terceiro ponto do nosso artigo.

\section{3 - A RESPONSABILIDAdE POLÍtICA: SEGUNDA VIA DE SUPERAÇÃO DO NIILISMO?}

Como vimos na ética do futuro postulada por Jonas, a relação dos pais para com os filhos emerge como arquétipo primordial da responsabilidade. De onde se segue que tal responsabilidade abre a possibilidade de continuidade da sobrevivência humana no futuro. Isso posto, essa forma de responsabilidade se estabelece como orientação e superação da realidade niilista em que vivemos. O dever dos pais para com o recém-nascido aponta a construção do futuro, mas em Jonas, a construção do futuro é um desafio que se impõe também ao homem público, cuja responsabilidade é em primeira instância livremente escolhida, de modo a 
ambicionar o poder em larga escala com vistas ao exercício da responsabilidade em um nível mais amplo. A responsabilidade política consiste na ampliação do raio de atuação do agente - o homem político. Mas a que se deve a necessidade de tal ampliação? A responsabilidade política é devedora da ideia de que esta ampliação está intimamente ligada à dimensão histórica, isto é, a preocupação fundamental neste momento está voltada ao futuro, pois implica a continuidade de uma identidade a qual também integra a responsabilidade coletiva, sendo esta, resultada daquela responsabilidade suprema exercida pelo homem político.

Se a sobrevivência da humanidade no futuro está condicionada à responsabilidade livremente assumida do homem político, como é o caso da responsabilidade parental, precisamos também destacar que ambas são correlatos do poder. Mas nas palavras de Jonas "é, sobretudo, o verdadeiro homo politicus quem ambiciona a responsabilidade ligada ao poder e tornada possível graças a ele, e que por isso ambiciona ambos ao mesmo tempo.” (PR.p.172). Segue-se daí que para o homem político, ambicionar o poder tem em vista assumir e realizar a responsabilidade em relação aos outros, sobretudo, para com aqueles que ainda não existem.

Assim sendo, como Jonas nos diz, "O homem público autentico estimará como sua glória (que pode lhe ser muito cara) precisamente que possa dizer dele que fez o melhor que pôde por aqueles sobre os quais detinha poder, ou seja, para aqueles em virtude de quem ele tinha poder." (Ibidem. p. 172). Portanto, em Jonas o poder emerge como fundamento da responsabilidade, mas não enquanto sobreposição. Em outros termos, trata-se do poder para e não do poder sobre. Desse modo, este último assumi o sentido de responsabilidade, cujo objetivo "é a res publica, a coisa pública, que em uma república é potencialmente a coisa de todos, mas realmente só o é nos limites do cumprimento dos deveres gerais da cidadania." (Ibidem. p. 172) Isso aponta para a necessidade do exercício da cidadania como condição para a efetivação da responsabilidade coletiva, que como dizíamos, integra também a responsabilidade política, cujo objetivo é justamente o de assegurar a sobrevivência de todos.

Daí se pode vislumbrar de fato a possibilidade de construção e efetivação do futuro como garantia de continuidade da espécie humana, tempo para o qual destina-se a elaboração ética de Jonas. E já que o futuro se estabelece como a ideia mestra que conduz o empreendimento ético jonasiano, logo, ele precisa ser preservado do perigo que hodiernamente representa o uso desmedido que se faz da técnica moderna. Por isso mesmo, nas palavras de Jonas, "o perigo que ameaça a comunidade em paralelo à convicção de que ele sabe o caminho para a salvação (e pode conduzi-la) torna-se um forte incentivo para que o homem corajoso se candidate e assuma a responsabilidade." (Ibidem, p. 172). Vê-se, pois, que paradoxalmente, o perigo que a técnica representa torna-se a mola propulsora para a responsabilidade, pois, a ameaça de catástrofe que 
resulta do afã do progresso utópico da técnica moderna nos conduz àquilo de Jonas chama de heurística do temor, que por sua vez faz com que seja despertado em nós o dever de prudência. Ou seja, "a mais sublime liberdade do eu conduz ao mais exigente e inclemente dos deveres." (Ibid, p.173). A partir disso emerge a urgência de responsabilidade, que por sua vez apela ao homem político para que este entre em cena e realize o que dele se espera, isto é, assumir num sentido amplo a responsabilidade no presente, com vistas à construção do futuro mediante o qual seja possível a continuidade da existência humana no mundo de amanhã.

A responsabilidade do homem político, consiste em tornar possível a vida coletiva no estado. Numa referência à posição aristotélica, Jonas afirma que

\begin{abstract}
o estado surge para tornar possível a vida humana e continua a existir para que a vida boa seja possível. Essas são também as preocupações do verdadeiro homem público. [...] O "homem público", no pleno sentido da palavra, ao longo da duração de seu mandato ou poder, assume a responsabilidade pela totalidade da vida da comunidade, por aquilo que costumamos chamar de bem público. (Ibid., p.180).
\end{abstract}

Nessa passagem, observa-se que a responsabilidade pela totalidade da vida assumida pelo homem público advém do seu poder como o correlato do seu agir responsável. Em outros termos, a responsabilidade está condicionada ao poder. Para o homem político diz Jonas, a conquista do poder deve visar objetivamente a responsabilidade. E "a dimensão dessa responsabilidade se assemelha à da responsabilidade parental: ela se estende da existência física aos mais elevados interesses, da segurança à plenitude, da boa condução até a felicidade." (Ibid., p.180). De onde se conclui que nesses dois âmbitos, com acento para o modelo parental, a responsabilidade neles empregadas constitui os arquétipos primordiais de toda responsabilidade, justamente porque elas visam o sujeito, num movimento que se inicia desde o Ser ao poder ser ${ }^{4}$ tanto no presente quanto, na continuidade do poder ser nos tempos vindouros.

Neste caso o ser e o poder ser do objeto, desperta o sentimento de responsabilidade dos pais em relação aos filhos, como também do homem público. Nas palavras de Jonas, "o homem público não é genitor da coletividade, cuja responsabilidade ele pretende assumir; ao contrário, é o fato de que ela já existe que lhe permite assumir tal responsabilidade e buscar o poder necessário para fazê-lo.” (Ibid., p.182). O poder é a mola propulsora da responsabilidade do homem público. Em outras palavras, a ação responsável do homem de estado está condicionada

\footnotetext{
$4 \mathrm{Ou}$ seja, tanto a responsabilidade estatal quanto a responsabilidade parental, além de visarem à existência da humanidade, asseguram as condições mediante as quais a humanidade continuará existindo. E isso não significa determinismo. Pois em Jonas esses arquétipos emergem como formas de assegurar o Ser, sendo que neste ser está contida a exigência de continuidade. Em outros termos, não basta somente assegurar o ser e permitir que, em termos futuros, ele seja apenas um ser em potencial. Como vimos, é necessário que seja garantida a vida do ser e concomitantemente o seu poder ser no futuro.
} 
ao seu poder, ambicionado numa escala mais ampla, de modo a assumir a responsabilidade também em escala mais ampla. O poder ambicionado pelo homem político impõe a exigência do fazer, isto é, a responsabilidade em ato, para que por meio dela, seja potencializada a responsabilidade de outros.

Assim sendo, a finalidade do poder que resulta na responsabilidade do homem político trata-se de corroborar o poder ser dos já existentes e também construir o futuro, com vistas à continuidade do poder ser das futuras gerações. E estando assegurada a continuidade destas, Jonas entende que a responsabilidade estaria assegurada no futuro, uma vez que o objetivo do projeto ético jonasiano é justamente garantir a possibilidade de que haja responsabilidade.

Ora, tal empreendimento se impõe como tarefa ao homem público, cuja arte de governar é, nas palavras de Jonas, “responsável por toda arte de governar no futuro”, (Ibid., p.201), ou dito de outra forma, uma das responsabilidades assumida pelo homem público - continua o filósofo, "é garantir que a arte de governar continue possível no futuro. [...] Aqui, o princípio é o de que toda responsabilidade integral, com seu conjunto de tarefas particulares, é responsável não apenas por cumprir-se, mas por garantir a possibilidade do agir responsável no futuro" (Ibidem., p.201). Portanto, como se pode observar, a continuidade da vida humana no futuro torna-se objeto da elaboração da empresa ética jonasiana. Por isso mesmo, o autor utiliza como arquétipos da responsabilidade que ele quer inaugurar, as responsabilidades: paterna e política. Elas abrirão o horizonte do futuro possibilitando então, a continuidade da espécie humana e com ela a continuidade da própria responsabilidade.

Em suma, ao homem político cabe realizar o que dele se espera, isto é, assumir num sentido amplo a responsabilidade no presente, com vistas à construção do futuro, de modo a assegurar a continuidade da espécie humana no mundo. Isso posto, podemos então concluir que sendo a tarefa do homem político a de cuidar da vida de forma ampla, esta, e igualmente aquela dos pais em relação aos filhos podem, portanto, se estabelecer tal como entende Jonas como os novos 'ecos', em substituição àqueles do niilismo relativista que tantas incertezas nos trazem.

\section{CONSIDERAÇÕES FINAIS}

Chegamos ao final de nossa reflexão e nela procuramos mostrar de que modo a técnica moderna e o niilismo que dela resulta, exige uma ética. Nossa exposição girou em torno de três pontos. No primeiro, mostramos o apogeu da técnica e o niilismo relativista como "ecos" da era moderna. Destacamos o niilismo como a falta de sentido que se insurge com o ruir dos valores transcendentes e convencionais. Neste caso, o que nos resta? Mostramos que, resta-nos uma 
realidade sem diretriz. O mundo não tem valor em si mesmo, antes sendo o seu valor tradicional, dado pelo homem - que por fim se tornará ele próprio um ser do qual não se pode dizer que seja também um fim em si, como bem o tem atestado a tecnologia e a biotecnologia moderna e isso leva a uma indiferença em relação ao ser e o não ser.

Destacamos que, se por um lado, a civilização tecnológica moderna celebra o triunfo da razão demonstrativa e operacional, por outro lado, ela assiste ao exílio da metafísica o que corrobora o niilismo relativista de nossos tempos. Dito de outro modo, o advento da técnica moderna impõe o niilismo metafísico e ético, como ecos do programa da técnica. Explicitamos que o que nos resta agora, é justamente um solo instável e um cenário que não nos aponta direções claras.

Ora, diante deste cenário de incertezas que a técnica moderna nos lega, sublinhamos que no pensamento de Hans Jonas, uma nova ética urge. Em Jonas, só uma ética metafisicamente fundamentada, é capaz de se colocar como possibilidade de resgate do ser - valor, portanto da metafísica. Entretanto, como alternativas ao niilismo, apresentamos as duas possíveis vias capazes de superá-lo: a responsabilidade dos pais em relação aos filhos - parental e a responsabilidade política (coletiva).

Como primeira via de superação do niilismo, analisamos a responsabilidade parental, cuja finalidade consiste em educar para tornar o filho adulto e responsável e isto representa um resgate da teleologia - valor, em tempos nos quais o afã tecnológico e biotecnológico, impõe o relativismo dos valores. Por isso, mostramos que a tarefa da responsabilidade parental é a de preservar o bem e o valor - cuidar da vida.

Nenhuma criança pede para nascer em qualquer que seja as situações, seja privilegiadas ou não. Porém, Jonas entende que o nascimento de uma criança representa o recomeço da humanidade, e isso abri a possibilidade de continuidade da existência de seres responsáveis no futuro longínquo. Eis o que se espera da responsabilidade enquanto dever fazer aplicada ao âmbito parental. Esta, portanto trata-se da primeira resposta ética, a qual exige a técnica e o niilismo relativista dos novos tempos.

Por ultimo, destacamos no último ponto de nossa reflexão, a responsabilidade estatal como resposta ética e segunda via de superação do niilismo. Mostramos que a preocupação de Jonas com a continuidade da humanidade e da responsabilidade além da esfera parental, se estende também ao âmbito político, por isso mesmo, vimos que ele propõe a responsabilidade política como segundo modelo paradigmático, a partir do qual torna-se possível pensar a ética e com isso reconduzir ao caminho de busca pela teleologia. 


\section{REFERÊNCIAS}

ARALDI, Clademir. O niilismo como doença da vontade humana. IHU On-Line. Revista do Instituto Humanistas Unisinos, São Leopoldo, 20 de dezembro de 2010 Edição 354.

COMÍN, G. Introdução. In: JONAS, H. Poder o impotencia de la subjetividad. Tardução de Illana Giner Comín. Coleção Pensamento Contemporâneo. Barcelona/Buenos Aires/México: Paidós, 2005.

HUXLEY, Alduos. O Admirável mundo novo. Lisboa, Portugal, Ed. Antígona, 2013, p. 307.

JONAS, Hans. O Princípio Responsabilidade: ensaio de uma ética para uma civilização tecnológica. Rio de Janeiro: Contraponto, PUC Rio, 2006.

—. Técnica, medicina e ética: sobre a prática do princípio responsabilidade. Trad. Grupo de trabalho Hans Jonas da ANPOF. São Paulo, Paulus, 2013.

. Memorias. Madrid: Editorial Losada, 2005.

LIMA VAZ, Claudio Henrique. Escritos de filosofia VII: Raízes da Modernidade. São Paulo, Loyola, 2002.

. Ética e razão moderna. Síntese, n. 68 (1995) 53-84.

LOPES, Wendell Evangelista Soares. A fundamentação metafísica do princípio responsabilidade em Hans Jonas. Belo Horizonte: Faculdade Jesuíta de Filosofia e Teologia, 2008.

NEDEL, José. Ética da Responsabilidade segundo Hans Jonas. In: Ética Aplicada. São Leopoldo: Unisinos. 2006, p. 146-147.

OLIVEIRA, Jelson. A interpretação analógica das relações entre niilismo gnóstico e niilismo existencialista segundo Hans Jonas. Síntese, Belo Horizonte, v. 41, n. 129, 2014.

POSSENTI, Vittorio. Nichilismo e Metafísica: Terza Navigazione. Roma, Armando, 1998.

RICOEUR, Paul. Ética e Filosofia da Biologia em Hans Jonas. In: Leituras 2: A região dos filósofos. SP: Edições Loyola, 1996, p. 229-244 [p. 229]. 
VATTIMO, Gianni. Morte de Deus e fim da metafísica: a luta contra os absolutos. $I H U$

On-Line. Revista do Instituto Humanistas Unisinos São Leopoldo, 20 de dezembro de 2010 Edição 354.

VOLPI, Franco. O Niilismo. São Paulo, Edições Loyola. Trad. Aldo Vannucchi, 1999. 